\title{
Preparation of dicholesteryl-derivatives: The effect of spatial configuration upon gelation
}

\author{
YAN Ni, ZHANG HeLan, XU ZhiYan \& FANG Yu ${ }^{*}$ \\ Key Laboratory of Applied Surface and Colloid Chemistry, Ministry of Education; School of Chemistry and Chemical Engineering,
} Shaanxi Normal University, Xi'an 710062, China

Received April 10, 2012; accepted June 25, 2012; published online September 12, 2012

\begin{abstract}
To investigate the effect of spatial configuration on the gelation properties of low molecular mass gelators (LMMGs), four novel di-cholesteryl derivatives have been specially designed and synthesized by introducing the cis-/trans-isomers of butene diacid and the optical isomers of $D / L$-phenylalanine into the linker between two cholesteryl moieties. These isomers have been denoted as $\mathrm{MaDC}, \mathrm{FaDC}$, MaLC and FaLC, respectively. The gelation properties of the compounds were examined in 26 organic solvents, and it was found that the trans-configuration is more favorable for the gelation, but the chirality of the linker shows little effect to the gelation. FaDC has the strongest gelation ability among the four isomers. Interestingly, FaDC and FaLC display phase-selective gelation of benzene, toluene and xylene from their mixtures with water at room temperature, which establishes a foundation for the purification of water contaminated by oil or aromatic solvents. SEM and CD spectroscopy studies revealed that the spatial configuration of the linkers of the gelators affects significantly the aggregation mode, the morphologies and the chirality of the network of the gels. Moreover, the different aggregation behaviors also have an impact on mechanical properties of the gels, which are consistent with the results from rheological studies. Furthermore, temperature- and concentration-dependent ${ }^{1} \mathrm{H}$ NMR and FTIR measurements demonstrated that intermolecular hydrogen bonding and $\pi-\pi$ stacking are the main driving forces for the formation of the gels.
\end{abstract}

low molecular mass gelators, spatial configuration, gelation, cholesterol, butene diacid

Citation: Yan N, Zhang H L, Xu Z Y, et al. Preparation of dicholesteryl-derivatives: The effect of spatial configuration upon gelation. Chin Sci Bull, 2012, 57: 4310-4321, doi: 10.1007/s11434-012-5449-8

Because of their potential applications in sensors, drug delivery devices, displays, oil recovery, controlled release, bioactivity maintenance, micro-/nano-materials preparation, and mild separation, etc. [1-12], low molecular mass gelators (LMMGs) have experienced a rapid development during the past two decades $[13,14]$. LMMGs can self-assemble into fibers, rods, ribbons, or other aggregates of different morphologies in suitable solvents $[14,15]$ through hydrogen bonding, $\pi-\pi$ stacking, van der Waals interaction, coordination interaction, and other kinds of supramolecular weak interactions, leading to the formation of networked structures, which are the bases of supramolecular gels [14]. Among many kinds of LMMGs [14] reported till now,

*Corresponding author (email: yfang@snnu.edu.cn) cholesteryl derivatives, as the first group of LMMGs [16], have attracted much attention from the very beginning. The cholesterol-based LMMGs can be classified into LS, $\mathrm{LS}_{2}$, ALS and $\mathrm{A}(\mathrm{LS})_{2}$ types according to the structures of aromatic moiety (A), steroid moiety (S), and functionalized linker (L) [17]. Our group has reported a series of work related to the design, synthesis and gelation behavior of cholesterol-based LMMGs, including all the four types, LS [18-20], $\mathrm{LS}_{2}$ [21-23], ALS [24,25], and A(LS) 2 [26,27]. In the studies, quite a large number of gel systems with unusual behaviors, such as gelation and phase-selective gelation at room temperature [23,26], redox response [25], gel emulsion [21], gel film formation [18,25], and $\mathrm{pH}$ response $[19,20]$, have been obtained, which may show potential application in corresponding fields in the future. 
Inspection of the reports relevant to the studies of cholesterol-based LMMGs, it can be seen that most of them have been created via introduction of various functional groups during the last few decades. Stereoisomerism, which can be classified into cis-trans isomerism (or geometric isomerism), optical isomerism and conformational isomerism, is of special importance among many properties of the functional groups. As for the cis-trans isomerism, azobenzene-based [28-33], stilbene-based [34-36] and butene diacid-based [37] gelators have attracted a great deal of attention due to the reversible sol-gel transition of the system achieved by the configurational change induced by light illumination. Žinić and coworkers [34-36] reported the first example of gelation induced by configurational isomerization, which is also the first example of gel preparation by converting a non-gelling compound to a gelator induced by light illumination. They also prepared bis(phenylalanine) maleic acid (1) and fumaric acid (2) amides and found that in water the non-gelling maleic acid amide (1) could be converted into gelling fumaric acid amide via photochemical treatment [37]. Zhang and colleagues [30] synthesized a series of new symmetric dicholesteryl gelators with an azobenzene unit in the linkers (DCAZO). Upon UV irradiation of a cyclopentanone gel of DCAZO, a trans-cis photoisomerization of the azobenzene structure occurred, resulting in gel-sol transition. Interestingly, the gel can be recovered by the reverse cis-trans photoisomerization after it is exposed to visible light. A variety of oxamide-based derivatives bearing a stilbene as a photochromic moiety has been prepared and their gelation properties investigated by Miljanić and coworkers [36]. The authors found that the trans-3a showed better gelation ability than its cis-isomer, and a controlled gelation by light was achieved through photo-responsive conformational changes of the stilbene part of trans-3a. According to the literatures, in most cases, the gel-sol transition occurs when the trans-isomer is photoisomerized to cis-isomer, indicating that the trans-configuration has stronger gelation ability than the cis-configuration. However, to our knowledge, there is only a little of report on the comparison of the gelation of the trans-isomer and cis-isomer in different solvents without the isomerization by external stimuli $[35,36]$, which will be worth studying.

The impact of optical isomerism, i.e. chirality, on assembled systems can be profound. It has been reported that chirality plays critical roles in assembling processes taking place on surfaces and interfaces, in liquid crystalline phase, and in the formation of supramolecular polymers and gels $[38,39]$. Shinkai and coworkers synthesized nineteen cholesteryl derivatives containing a variety of azobenzene moieties coupled to $(S)$ - and $(R)-\mathrm{C}-3$ of a steroidal moiety through an ester linkage. They found that the gelation ability was fairly different between $S$-isomer and its corresponding $R$-isomer, and investigated the difference via CD spectra [31]. Our group reported the gelation of eight new diacid amides of dicholesteryl $L(D)$-alaninates. We found that an inverse in the chirality of the amino acid residue can produce a dramatic change in the gelation behavior of the compounds and the microstructures of the gels [22].

Although there are some reports on the gelation of compounds with different cis-trans isomer and optical isomer, respectively, the example of the effect of the combination of these two stereo-isomers on the gelation is rare. Thus, purposeful creation of compounds containing the two kinds of stereo-isomers is still a challenge. On the bases of the above discussion and consideration, and as a continuation of our efforts in the search of new LMMGs with superior properties, in the present study, we chose maleic/fumaric acid as the cis-trans isomeric moieties and $D / L$-phenylalanine as the optical isomeric moieties, and chemically attached them into cholesterol, and prepared four novel dicholesterolbased LMOGs of $\mathrm{LS}_{2}$ type (Scheme 1). We reported here the effect of the spatial configuration on the gelation.

\section{Experimental}

\subsection{Materials}

Cholesterol, boc- $D$-phenylalaninate, boc- $L$-phenylalaninate, maleic acid, fumaric acid, dicyclohexylcarbodimide (DCC), and $\mathrm{N}, \mathrm{N}$-dimethylamino-pyridine (DMAP) were supplied from the Sinopharm Chemical Reagent Co., Ltd, and used without further purification. All solvents used in the syntheses were purified, dried, or freshly distilled as required.

\subsection{Instruments and procedures}

(1) Gelation test. A known weight of the compound to be tested and a measured volume of selected pure solvent were placed into a sealed test tube and the system was heated in an oil bath until the solid was dissolved, then, the solution was cooled to room temperature in air, and finally the test tube was inversed to look at if the solution inside could still flow. A positive test is obtained if the flow test is negative. Some of the gels obtained are opaque (OG), some are transparent (TG). And some other gels could not flow down but would be broken by flicking, so, this kind of gel is denoted as WG (weak gel). In some cases, solution and gel may coexist within a system. This kind of system is referred to as "partial gel" (PG). For systems, in which only solution was remained until the end of the tests, they were referred to as solution ( $\mathrm{S})$. When the gelator of a system appeared as precipitate, the system was denoted as "P". The system, in which the potential gelator could not be dissolved even at the boiling point of the solvent, was called an insoluble system (I).

(2) Gel-sol phase transition temperatures $\left(T_{\text {gel }}\right) . \quad T_{\text {gel }}$ was determined by the falling drop method [40] as the temperature range over which the gels (in the inverted tubes) fell under the influence of gravity when heated at $\sim 2^{\circ} \mathrm{C} / \mathrm{min}$ in a water bath. 


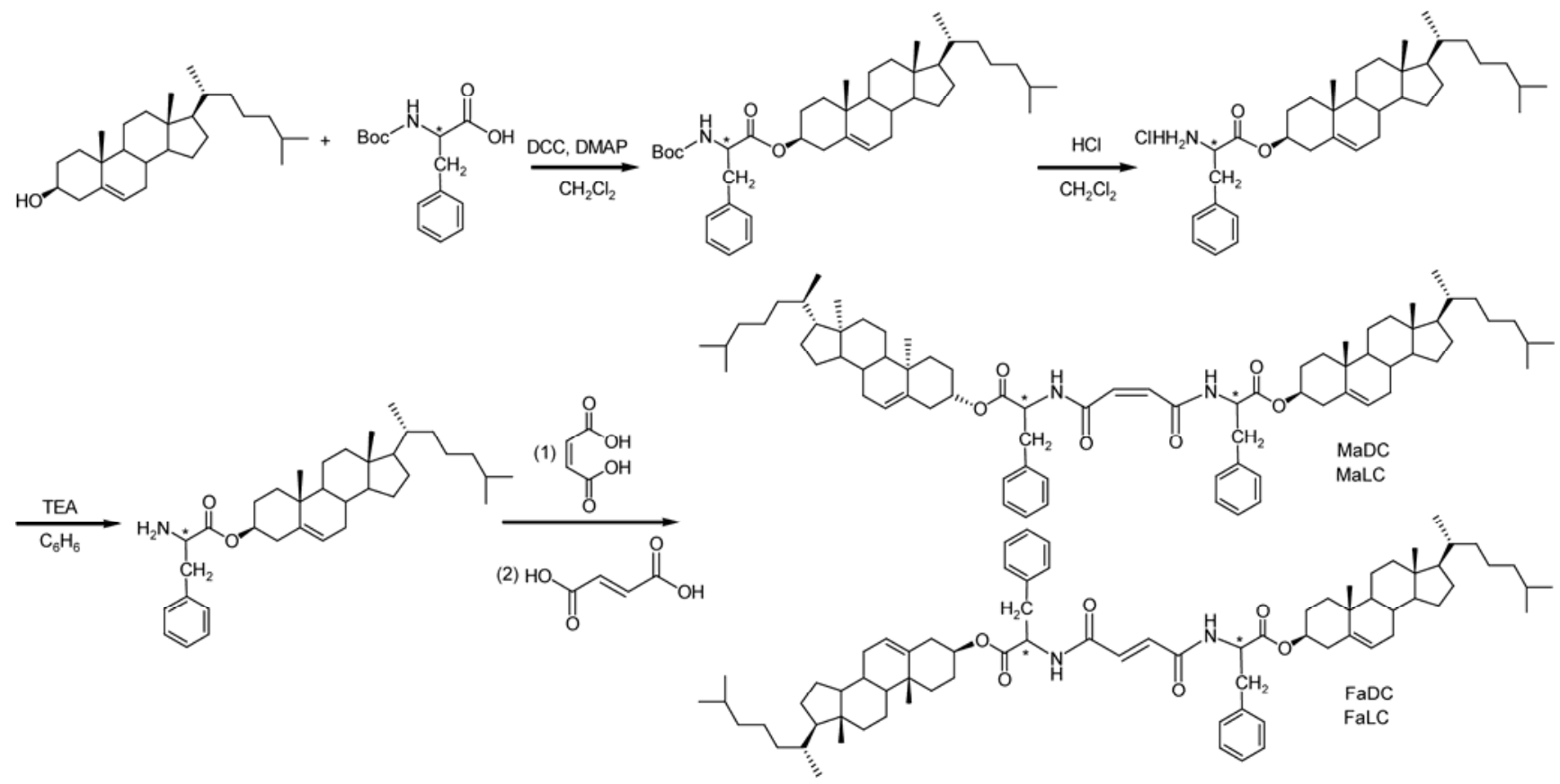

Scheme 1 Synthesis routine of the diacid amides of dicholesteryl $D / L$-phenylalaninate.

(3) Scanning electron microscopy (SEM) measurement. SEM pictures of the xerogels were taken on a Quanta 200 scanning electron microscopy spectrometer (Philips-FEI). The accelerating voltage was $20 \mathrm{kV}$, and the emission was $10 \mathrm{~mA}$. Xerogels were prepared by freezing gels in liquid nitrogen and then evaporated by a vacuum pump for $24 \mathrm{~h}$. Prior to examination, the xerogel was attached to a copper holder by using conductive adhesive tape, and then it was coated with a thin layer of gold.

(4) Polarized optical micrographs (POMs). POMs were recorded on a Leitz 585 SM-LUX-POL microscope equipped with crossed polars, a Leitz 350 heating stage, a photometrics CCD camera interfaced to a computer, and an Omega HH503 microprocessor thermometer connected to a J-K-T thermocouple. The samples for POM were flame sealed in 0.4 or $0.5 \mathrm{~mm}$ path-length, flattened Pyrex capillary tubes (VitroCom) heated to their liquid phase in a boiling water bath and kept in the water bath while the liquid returned slowly to room temperature (about $5^{\circ} \mathrm{C} / \mathrm{min}$ ).

(5) ${ }^{1} \mathrm{H}$ NMR measurements. ${ }^{1} \mathrm{H}$ NMR data of samples were collected on AVANCE $300 \mathrm{MHz}$ spectrometer (Bruker).

(6) FTIR measurements. The FTIR spectra of solution and gel samples were recorded in transmission mode using a Bruker Equinox 55 infrared spectrometer. The gel sample for measurement was prepared by coating it on a $\mathrm{KBr}$ slice as a smooth film and then freeze-dried. Solution sample was prepared by dropping it on a $\mathrm{KBr}$ slice and then freezedried.

(7) Rheological measurements. Rheological measurements were performed by using a stress-controlled rheometer (TA instrument ARG2) equipped with aluminum-coated parallel-plate geometry $(20 \mathrm{~mm}$ diameter, $1.00 \mathrm{~mm}$ gap between the two plates). A solvent trapping device was placed above the plate to avoid evaporation. All measurements were conducted at $20^{\circ} \mathrm{C}$. The first step of an experiment consists of determining the so-called linear viscoelastic region of the gel. This was done by measuring the storage modulus $G^{\prime}$, associated with the energy storage, and the loss modulus $G^{\prime \prime}$, associated with the loss of energy, as a function of the stress amplitude. The linear region is such that both dynamic moduli are independent of the stress amplitude and reflect the properties of the unperturbed network. In that region, $G^{\prime}$ and $G^{\prime \prime}$ are measured as functions of the oscillatory shear stress. In the second step of the experiment, the modulus as a function of frequency was measured from 0.1 to $100 \mathrm{~Hz}$ at a constant shear stress of $1 \mathrm{~Pa}$ in the linear region.

(8) Circular dichroism (CD) measurements. CD spectra were obtained using chirascan circular dichroism spectrometer. In the spectral measurement, the concentration of a gel was adjusted to its critical gelator concentration (CGC), and the temperature was controlled at room temperature $\left(20^{\circ} \mathrm{C}\right)$. The hot solution was poured into a quartz cell $(1$ $\mathrm{mm}$ ) and cooled to room temperature to form a stable gel. The temperature-dependent UV-Vis and CD spectra were recorded from low temperature to high temperature. The temperature of sample system was increased in steps of $5^{\circ} \mathrm{C} / \mathrm{min}$, allowing ample equilibration time after each increase to a maximum of $40^{\circ} \mathrm{C}$. During the measurements, quartz cells were carefully sealed. It was found that the volume of the solvent did not change significantly after each measurement.

(9) Purification efficiency. The purification efficiency was determined by fluorescence measurement conducted on 
a time-correlated single-photon-counting FLS 920 fluorescence spectrometer (Edinburgh). The path length of the quartz cell is $1 \mathrm{~cm}$. The purification efficiency was calculated by using an equation like $E=\left(I_{0}-I\right) / I_{0}$, where $I_{0}$ and $I$ stand for the fluorescence intensity of the system before and after the purification, respectively.

\subsection{Synthesis of the gelators}

(1) Synthesis of MaDC and MaLC. The synthesis routine is shown in Scheme 1. Cholesteryl $D$-phenylalaninate primary amine was synthesis according to a previous report [20,41]. Maleic acid $(0.232 \mathrm{~g}, 2 \mathrm{mmol})$ was dissolved in $20 \mathrm{~mL}$ tetrahydrofuran (THF), and then $40 \mathrm{~mL}$ of THF solution containing $2.135 \mathrm{~g}$ (4 mmol) of cholesteryl phenylalaninate primary amine and DCC $(0.824 \mathrm{~g}, 4 \mathrm{mmol})$ was added drop-wise to the above solution with stirring. The reaction mixture was stirred at $0^{\circ} \mathrm{C}$ for $10 \mathrm{~h}$. After the reaction, the mixture was filtered, the filtrate was evaporated to dryness, and the resulting solid was washed with hot methanol for three times, and dried in vacuum to give the desired product in $30 \%$ yield as a white or yellowish powder. Satisfactory results were obtained.

For MaDC: m.p. $189.5-191.5^{\circ} \mathrm{C} .{ }^{1} \mathrm{H}$ NMR $\left(\mathrm{CDCl}_{3} /\right.$ $\mathrm{Me}_{4} \mathrm{Si}, 300 \mathrm{MHz}$ ): $\delta$ 8.32-8.35 (m, CONH, 2H), 7.15-7.17 $(\mathrm{m}$, benzyl, 10H), 6.08 (s, CO-CH=CH-CO, 2H), $5.36(\mathrm{~s}$, alkenyl, 2H), 4.82-4.84 (d, $\left.\mathrm{CH}\left(\mathrm{C}_{6} \mathrm{H}_{5}\right) \mathrm{COO}, 2 \mathrm{H}\right), 4.59$ (d, oxycyclohexyl, 2H), 3.14 (s, $\left.-\mathrm{CH}_{2}\left(\mathrm{C}_{6} \mathrm{H}_{5}\right), 4 \mathrm{H}\right), 0.68-2.30$ (m, cholesteryl protons, $86 \mathrm{H})$. IR $(\mathrm{KBr}) v\left(\mathrm{~cm}^{-1}\right): 3230\left(v_{\mathrm{N}-\mathrm{H}}\right.$, amide $), 1738\left(v_{\mathrm{C}=\mathrm{O}}\right.$, ester $), 1666\left(v_{\mathrm{C}=\mathrm{O}}\right.$, amide $\left.\mathrm{I}\right), 1556\left(\delta_{\mathrm{N}-\mathrm{H}}\right.$, amide II). Elemental analysis (\%) calcd for $\mathrm{C}_{76} \mathrm{H}_{110} \mathrm{~N}_{2} \mathrm{O}_{6}: \mathrm{C}$, 79.53; H, 9.66; N, 2.44; Found: C, 79.28; H, 9.49; N, 2.24.

For MaLC: Yield 55\%, m.p. 201.5-202.5 ${ }^{\circ} \mathrm{C} .{ }^{1} \mathrm{H}$ NMR $\left(\mathrm{CDCl}_{3} / \mathrm{Me}_{4} \mathrm{Si}, 300 \mathrm{MHz}\right): \delta 8.33-8.35(\mathrm{~m}, \mathrm{CONH}, 2 \mathrm{H})$, 7.16-7.18 (m, benzyl, 10H), 6.07 (s, CO-CH=CH-CO, 2H), 5.36 (s, alkenyl, $2 \mathrm{H}), 4.82-4.84\left(\mathrm{~d}, \mathrm{CH}\left(\mathrm{C}_{6} \mathrm{H}_{5}\right) \mathrm{COO}, 2 \mathrm{H}\right)$, 4.60 (d, oxycyclohexyl, 2H), 3.14-3.15 (d, $-\mathrm{CH}_{2}\left(\mathrm{C}_{6} \mathrm{H}_{5}\right)$, $4 \mathrm{H}), 0.68-2.25$ (m, cholesteryl protons, $86 \mathrm{H}$,). IR (KBr) $v$ $\left(\mathrm{cm}^{-1}\right): 3390\left(v_{\mathrm{N}-\mathrm{H}}\right.$, amide $), 1738\left(v_{\mathrm{C}=\mathrm{O}}\right.$, ester $), 1633\left(v_{\mathrm{C}=\mathrm{O}}\right.$, amide I), $1529\left(\delta_{\mathrm{N}-\mathrm{H}}\right.$, amide II). Elemental analysis $(\%)$ calcd for $\mathrm{C}_{76} \mathrm{H}_{110} \mathrm{~N}_{2} \mathrm{O}_{6}: \mathrm{C}, 79.53 ; \mathrm{H}, 9.66 ; \mathrm{N}, 2.44$; found: $\mathrm{C}$, $79.14 ; \mathrm{H}, 9.73 ; \mathrm{N}, 2.25$.

(2) Synthesis of FaDC and FaLC. The procedures used for the preparation of $\mathrm{FaDC}$ and $\mathrm{FaLC}$ are similar to that for MaDC. Satisfactory results were obtained.

For FaDC: Yield 48\%, m.p. 205.0-206.5 ${ }^{\circ} \mathrm{C} .{ }^{1} \mathrm{H}$ NMR $\left(\mathrm{CDCl}_{3} / \mathrm{Me}_{4} \mathrm{Si}, 300 \mathrm{MHz}\right): \delta 7.10-7.13(\mathrm{~m}$, benzyl, $10 \mathrm{H})$, 6.99 (s, CO-CH=CH-CO, 2H), 6.62-6.65 (m, CONH, 2H), 5.35 (s, alkenyl, $2 \mathrm{H}), 4.93-4.95\left(\mathrm{~d}, \mathrm{CH}\left(\mathrm{C}_{6} \mathrm{H}_{5}\right) \mathrm{COO}, 2 \mathrm{H}\right)$, 4.60 (d, oxycyclohexyl, $2 \mathrm{H}), 3.12-3.13\left(\mathrm{~s},-\mathrm{CH}_{2}\left(\mathrm{C}_{6} \mathrm{H}_{5}\right), 4 \mathrm{H}\right)$, 0.68-2.28 (m, cholesteryl protons, $86 \mathrm{H}$,). IR (KBr) $v\left(\mathrm{~cm}^{-1}\right)$ : $3299\left(v_{\mathrm{N}-\mathrm{H}}\right.$, amide $), 1736\left(v_{\mathrm{C}=\mathrm{O}}\right.$, ester $), 1640\left(v_{\mathrm{C}=\mathrm{O}}\right.$, amide $\left.\mathrm{I}\right)$, $1539\left(\delta_{\mathrm{N}-\mathrm{H}}\right.$, amide II). Elemental analysis $(\%)$ calcd for $\mathrm{C}_{76} \mathrm{H}_{110} \mathrm{~N}_{2} \mathrm{O}_{6}$ : C, 79.53; H, 9.66; N, 2.44; found: C, 78.78; H,
9.53; N, 2.32.

For FaLC: Yield $63 \%$, m.p. $185.0-187.0^{\circ} \mathrm{C} .{ }^{1} \mathrm{H}$ NMR $\left(\mathrm{CDCl}_{3} / \mathrm{Me}_{4} \mathrm{Si}, 300 \mathrm{MHz}\right): \delta$ 7.11-7.13 (m, benzyl, $\left.10 \mathrm{H}\right)$, 6.92 (s, CO-CH=CH-CO, 2H), 6.51-6.54 (m, CONH, 2H), 5.37 (s, alkenyl, 2H), 4.92-4.94 (d, $\left.\mathrm{CH}\left(\mathrm{C}_{6} \mathrm{H}_{5}\right) \mathrm{COO}, 2 \mathrm{H}\right)$, 4.61 (d, oxycyclohexyl, $2 \mathrm{H}), 3.10-3.14$ (s, $\left.-\mathrm{CH}_{2}\left(\mathrm{C}_{6} \mathrm{H}_{5}\right), 4 \mathrm{H}\right)$, 0.68-2.29 (m, cholesteryl protons, $86 \mathrm{H}$,). IR $(\mathrm{KBr}) v\left(\mathrm{~cm}^{-1}\right)$ : $3294\left(v_{\mathrm{N}-\mathrm{H}}\right.$, amide $), 1736\left(v_{\mathrm{C}=\mathrm{O}}\right.$, ester $), 1641\left(v_{\mathrm{C}=\mathrm{O}}\right.$, amide $\left.\mathrm{I}\right)$, $1541\left(\delta_{\mathrm{N}-\mathrm{H}}\right.$, amide II). Elemental analysis $(\%)$ calcd for $\mathrm{C}_{76} \mathrm{H}_{110} \mathrm{~N}_{2} \mathrm{O}_{6}$ : C, 79.53; H, 9.66; N, 2.44; found: C, 78.76; H, $9.40 ; \mathrm{N}, 2.20$.

\section{Results and discussion}

\subsection{Gelation properties}

The gelation behaviors of these compounds have been tested in 26 solvents with $2.5 \%(\mathrm{w} / \mathrm{v})$ as a standard concentration. The results are summarized in Table 1 . With reference to

Table 1 Gelation behaviors of dicholesteryl derivatives in various organic solvents ${ }^{\text {a) }}$

\begin{tabular}{|c|c|c|c|c|}
\hline Solvents & $\mathrm{MaDC}$ & $\mathrm{FaDC}$ & MaLC & FaLC \\
\hline Methanol & I & I & I & I \\
\hline Ethanol & I & I & I & I \\
\hline 1-Propanol & $\mathrm{P}$ & $\mathrm{P}$ & $\mathrm{P}$ & OG \\
\hline 1-Butanol & $\mathrm{P}$ & OG & PG & OG \\
\hline 1-Pentanol & PG & OG & PG & OG \\
\hline 1-Hexanol & PG & OG & WG & OG \\
\hline 1-Heptanol & $\mathrm{P}$ & OG & PG & OG \\
\hline 1-Octanol & PG & OG & PG & OG \\
\hline 1-Nonanol & $\mathrm{P}$ & OG & PG & OG \\
\hline 1-Decanol & PG & OG & PG & OG \\
\hline$n$-Pentane & I & I & I & I \\
\hline$n$-Hexane & I & I & I & I \\
\hline$n$-Heptane & I & I & I & I \\
\hline n-Octane & $\mathrm{P}$ & OG & I & OG \\
\hline$n$-Nonane & $\mathrm{P}$ & OG & WG & OG \\
\hline$n$-Decane & $\mathrm{P}$ & OG & WG & OG \\
\hline Cyclohexane & $\mathrm{P}$ & $\mathrm{OG}^{*}$ & WG & $+\mathrm{OG}^{*}$ \\
\hline Kerosene & $\mathrm{P}$ & OG & OG & OG \\
\hline Benzene & S & $\mathrm{TG}^{*}$ & S & $\mathrm{OG}^{*}$ \\
\hline Toluene & $\mathrm{P}$ & $\mathrm{TG}^{*}$ & PG & $\mathrm{OG}^{*}$ \\
\hline Xylene & $\mathrm{P}$ & $\mathrm{TG}^{*}$ & $\mathrm{P}$ & $\mathrm{TG}^{*}$ \\
\hline $\mathrm{CCl}_{4}$ & $\mathrm{~S}$ & $\mathrm{OG}^{*}$ & $\mathrm{~S}$ & $\mathrm{P}$ \\
\hline Diethyl ether & $\mathrm{P}$ & OG & OG & $\mathrm{P}$ \\
\hline Acetone & I & $\mathrm{OG}^{*}$ & I & $+\mathrm{OG}^{*}$ \\
\hline DMSO & OG & $\mathrm{OG}^{*}$ & OG & PG \\
\hline DMF & $\mathrm{P}$ & OG & OG & $\mathrm{P}$ \\
\hline
\end{tabular}

a) Concentration of gelator: $2.5 \%(\mathrm{w} / \mathrm{v})$; S: solution; I: insoluble; OG: Opaque gel; TG: transparent gel; WG: weak gel; PG: partial gel; P: precipitate; $\mathrm{G}^{*}$ : gels forming at room temperature without heating; +: gels forming with sonication. 
the table, it can be seen that MaDC has the poorest gelation ability among the four compounds in the organic solvents tested, since it can only gelate DMSO. On the other hand, although FaDC, MaLC and FaLC are all versatile gelators, for the solvents gelated by them range from high polar solvents like DMSO and DMF to apolar solvents, such as $n$ nonane, $n$-decane and kerosene, the gelation ability of these three isomers is very different from each other. Firstly, the numbers of solvents gelated by FaDC, MaLC and FaLC are 20,8 and 17 of the 26 solvents tested, respectively. Secondly, generally speaking, a LMOG gel forms during the process of heating and cooling cycle of the gelator-solvent system. However, some of the gels listed in Table 1 can form spontaneously at room temperature without heatingcooling process. We can see that FaDC can gelate 7 solvents spontaneously, FaLC can form 5 room-temperature gels, but none of the solvents tested can be gelated by MaDC or MaLC without heating and cooling at room temperature. It is obvious that $\mathrm{FaDC}$ is superior to others in gelation among the four isomers.

As the chemical compositions of the four compounds are exactly the same, and the goal of our present work is to study the effect of the spatial configuration (cis-trans isomerism and optical isomerism) of the gelators on the gelation, it is necessary for us to compare the gelation behaviors of the cis- and trans-isomers as well as the $D$ - and $L$-isomers. With careful reference to Table 1 and paying more attention to the cis-trans isomerism, it should be not difficult to find that the trans-isomers are more effective gelators. As for FaDC and FaLC, they form 37 gels including 12 room temperature gels compared with 9 gels formed by the cis-isomers, $\mathrm{MaDC}$ and MaLC, suggesting that the trans-configuration is more helpful for the gelation, which is consistent with the results of literatures [28-37]. This may be understood by considering that the change in molecular configuration leads to the weakening of van der Waals interaction between cholesteryl moieties [30] as well as breaking or reforming of the hydrogen bonding [28,29] in cis-isomer, thus making cis-isomers dissolve or form partial gels in most of the solvents which can be gelled by trans-isomers. As for the chirality, the numbers of the gels formed by $D$-isomers (21) and $L$-isomers (25) are very similar, demonstrating that the chirality is not the main factor affecting the gelation ability of the four isomers. It provides the clear-cut evidence that the formation of the gel depends on the configurational properties of compounds even though they have the same chemical composition [37].

Other evidences for the more efficient gelation ability of trans-configuration are $T_{\text {gel }}$ and CGC. We took the systems of MaDC, FaDC and MaLC in DMSO, FaDC, MaLC and MaLC in $n$-nonane as well as FaDC, MaLC and MaLC in $n$-decane as examples to study $T_{\text {gel }}$ and CGC, and the results are shown in Table 2. We can find that, in most cases, the $T_{\text {gel }}$ of the gels of the trans-isomers is higher than that of the corresponding cis-isomer gels, and the CGCs of the transisomers are lower than those of corresponding cis-isomers, suggesting again that trans-isomers are more effective gelators than $c i s$-isomers.

\subsection{Morphology}

To estimate the impact of the spatial configuration of the compounds on the morphologies of different gels, the xerogels prepared by freeze-drying of some gels of these four isomers in different solvents $(2.5 \%, \mathrm{w} / \mathrm{v})$ were studied via SEM. Figure 1 shows some typical SEM images of the xerogels. As expected, the different cis-trans isomers of the gelators resulted in very different microstructures of the xerogels, as evidenced by the differences between the SEM images of MaDC/DMSO and FaDC/DMSO, MaDC/cyclohexane and $\mathrm{FaDC} / \mathrm{cyclohexane}$. Likewise, the impact of the different inherent chirality of the gelators on the morphology was displayed by the varied morphologies of the xerogels of MaDC/DMSO and MaLC/DMSO, FaDC/cyclohexane and FaLC/cyclohexane, as well as FaDC/benzene and FaLC/ benzene. These findings indicate clearly that the slight change in the spatial configuration of the linkers between the two cholesteryl moieties of each compound shows a significant effect on the morphologies [22,37]. This conclusion is also supported by the results from polarized optical microscopy (POM) studies of the gels of MaDC/DMSO, FaDC/DMSO and MaLC/DMSO (Figure 2).

On the other hand, the morphologies of the xerogels of the same compound in different solvents show a remarkable difference, such as the xerogels of FaDC in DMSO, cyclohexane and benzene, suggesting that the microstructures of the gels also depends on the nature of the solvents gelated (Figure 1).

Table $2 T_{\text {gel }}\left({ }^{\circ} \mathrm{C}\right)$ of the $2.5 \%(\mathrm{w} / \mathrm{v})$ gels and the CGCs $(\%$, w/v) of dicholesteryl derivatives in DMSO, $n$-nonane and $n$-decane

\begin{tabular}{|c|c|c|c|c|c|c|}
\hline & \multicolumn{2}{|c|}{ DMSO } & \multicolumn{2}{|c|}{$n$-nonane } & \multicolumn{2}{|c|}{$n$-decane } \\
\hline & $T_{\text {gel }}$ & CGC & $T_{\text {gel }}$ & $\mathrm{CGC}$ & $T_{\text {gel }}$ & CGC \\
\hline $\mathrm{MaDC}$ & $64-65$ & 1.1 & - & - & - & - \\
\hline $\mathrm{FaDC}$ & $92-93$ & 1.0 & $144-145$ & 0.8 & $154-155$ & 1.3 \\
\hline MaLC & $105-106$ & 1.2 & $30-31$ & 2.3 & $32-33$ & 2.4 \\
\hline FaLC & - & - & $121-122$ & 1.5 & $115-116$ & 1.5 \\
\hline
\end{tabular}



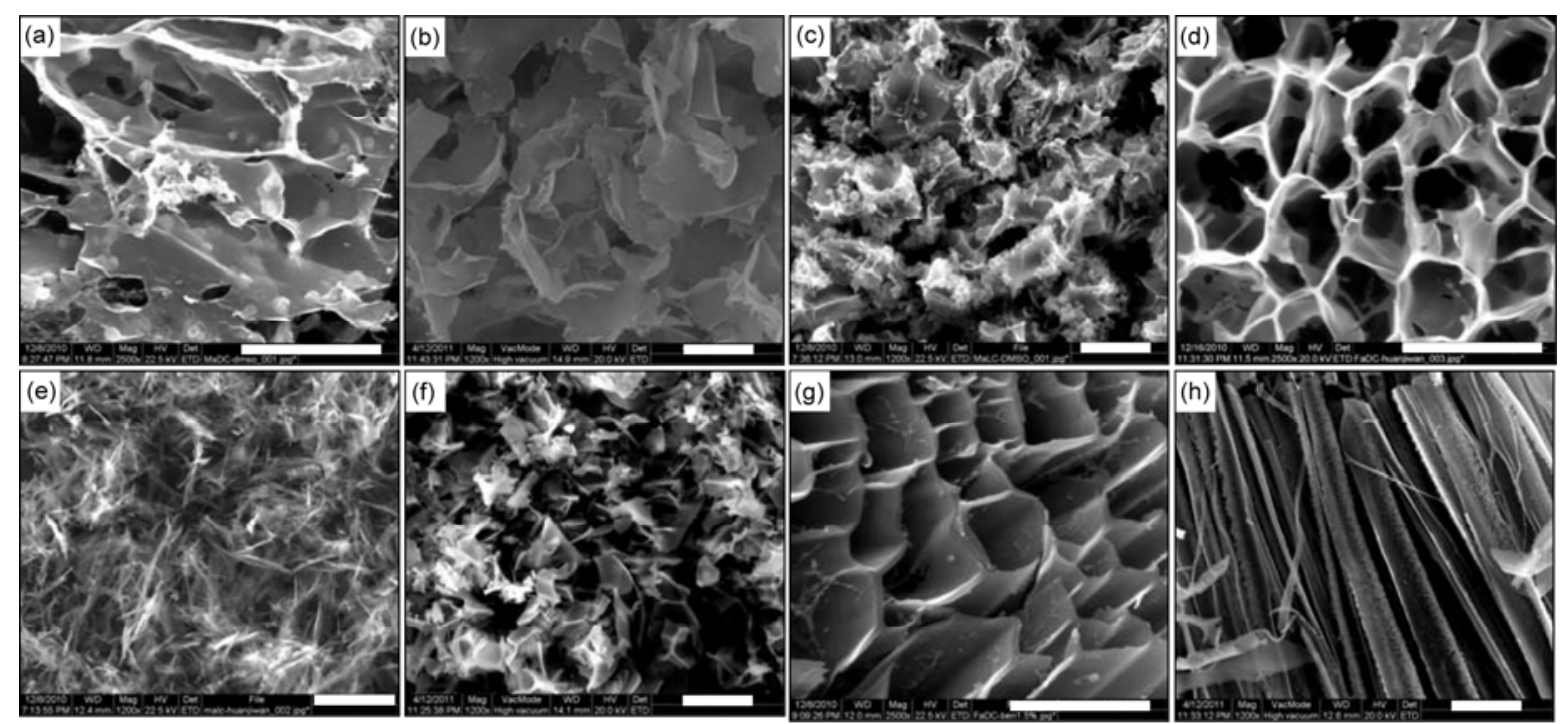

Figure 1 SEM images of the xerogels of MaDC/DMSO (a), FaDC/DMSO (b), MaLC/DMSO(c), FaDC/cyclohexane (d), MaLC/cyclohexane (e), FaLC/ cyclohexane (f), FaDC/benzene (g), and FaLC/benzene (h). [gelator]=2.5\% (w/v). bar=20 $\mu \mathrm{m}$.
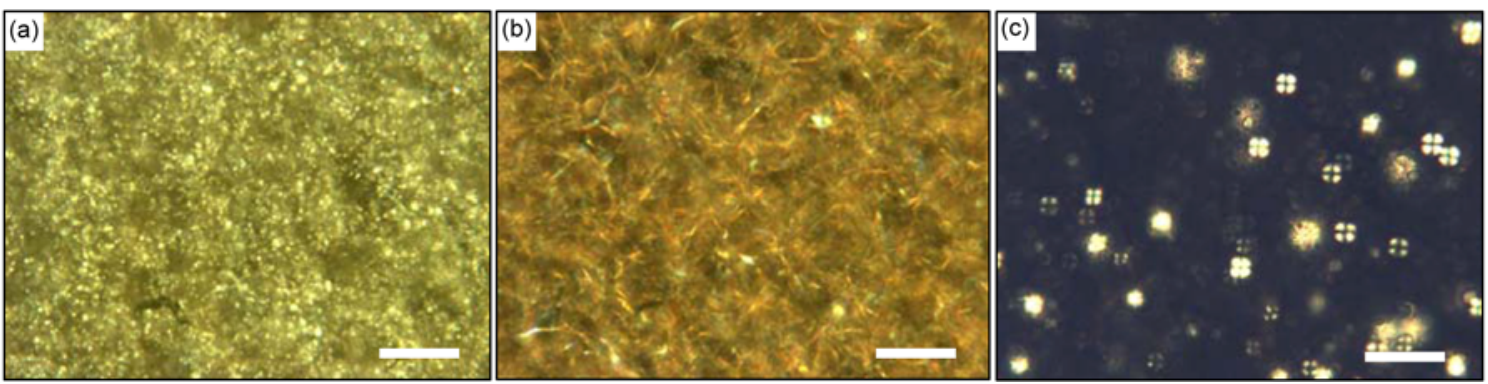

Figure 2 Polarized optical micrographs (POM) of gels of $2.5 \mathrm{wt} \% \mathrm{MaDC}$ (a), FaDC (b) and MaLC (c) in DMSO. bar=100 $\mu \mathrm{m}$.

\subsection{CD spectroscopy}

It is known that circular dichroism (CD) appears when the chromophoric moieties of LMMG molecules self-assemble in an appropriate orientation. Thus, CD spectroscopy measurements for FaDC and FaLC in solution as well as in gel states were performed in order to investigate the expression of chirality and the order in the self-assemblies of gelators in a gel phase. For the present study, the investigation was performed at a concentration of $1.0 \%(\mathrm{w} / \mathrm{v})$ using THF or benzene as solvents. The corresponding $\mathrm{CD}$ spectra are shown in Figure 3(a). It is obvious that the gel phase is CD-active whereas the sol phase is totally CD-silent [31]. For example, there is no $\mathrm{CD}$ signal for $\mathrm{FaDC} / \mathrm{THF}$ solution or FaLC/THF solution. However, strong CD signals were detected in the gels of both FaDC/benzene and FaLC/benzene. Importantly, the intensity of the CD signal for the gel of FaLC/benzene decreased gradually and eventually disappeared upon increasing the temperature from 20 to $40^{\circ} \mathrm{C}$ (Figure 3(b)), indicating that the CD signal observed in the gel state originated from the chirality of the network structures rather than from the inherent chirality of the gelators. Upon further examination of the CD spectra in Figure 3(a), it can be observed that the $\mathrm{CD}$ signal of FaDC gel is negative, whereas that of FaLC gel is positive, suggesting that the chiralities of the assemblies in the two kinds of gels are opposite. Obviously, this difference can be attributed to the difference in the chirality of the amino acid residues in the gelators [22].

\subsection{Rheological studies}

Although most of the gels in Table 1 are formed via heatingcooling procedure, some of them show remarkable thixotropic property at $20^{\circ} \mathrm{C}$, which is important for the potential applications of the gels. Thus, we studied the flow behavior of these gels by comparing their rheological properties [42]. It is well-known that the two rheological criteria required for a gel are (i) the dynamic elastic modulus, $G^{\prime}$, associated with the energy storage, exceeding the loss modulus $G^{\prime \prime}$, associated with the loss of the energy, by at least one order of magnitude, and (ii) the independence of $G^{\prime}$ on the oscillatory frequency $[43,44]$.

Firstly, to investigate the effect of chirality upon the mechanical properties of the gels, the gels of FaDC and FaLC in $n$-nonane $(2 \%, \mathrm{w} / \mathrm{v})$ were selected as examples, and their 

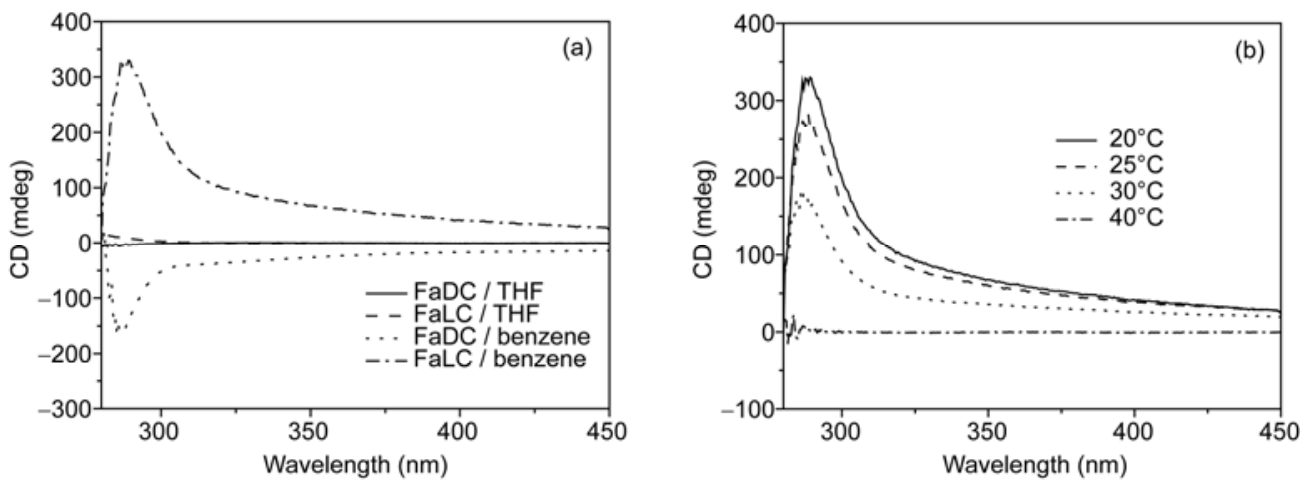

Figure $3 \mathrm{CD}$ spectra of $\mathrm{FaDC}$ and $\mathrm{FaLC}$ in THF solution and benzene gel phase (1.0\%, w/v) at room temperature (a), and temperature-dependent $\mathrm{CD}$ spectra of FaLC/benzene gel $(1.0 \%, w / v)(b)$.

$G^{\prime}$ and $G^{\prime \prime}$ were measured as functions of shear stress at room temperature. The results are shown in Figure 4. It can be seen for both systems that initial $G^{\prime}$ is higher than $G^{\prime \prime}$ by around one order of magnitude, suggesting the presence of gel phase. With a gradual increase in the applied stress, both $G^{\prime}$ and $G^{\prime \prime}$ remained invariant and then beyond a certain stress, defined as the yield stress, they deviated from linearity, demonstrating that gels began to flow $[42,45]$. The yield stresses for FaDC and FaLC were estimated to be 70 and 11 $\mathrm{Pa}$, respectively. The ratio of $G^{\prime} / G^{\prime \prime}$ at shear stress $=0.1 \mathrm{~Pa}$ was also found to be higher for FaDC (14.31) than that for FaLC (6.92). Thus, the rheological data clearly revealed better mechanical stability for FaDC gel, which corresponds with the observation that the gel from FaDC possesses higher thermo-stability as revealed by higher $T_{\text {gel }}$ value $\left(137-138^{\circ} \mathrm{C}\right.$ for $2.0 \%(\mathrm{w} / \mathrm{v}) \mathrm{FaDC} / n$-nonane gel compared with $118-119^{\circ} \mathrm{C}$ for $2.0 \%$ (w/v) $\mathrm{FaLC} / n$-nonane gel).

Then, $\mathrm{FaDC} / n$-nonane system was chosen to investigate the importance of gelator concentration to the rheological properties of a supramolecular gel. The $G^{\prime}$ values of $\mathrm{FaDC} /$ $n$-nonane systems at different concentrations are shown in Figure 5 as functions of shear stress amplitude. From the

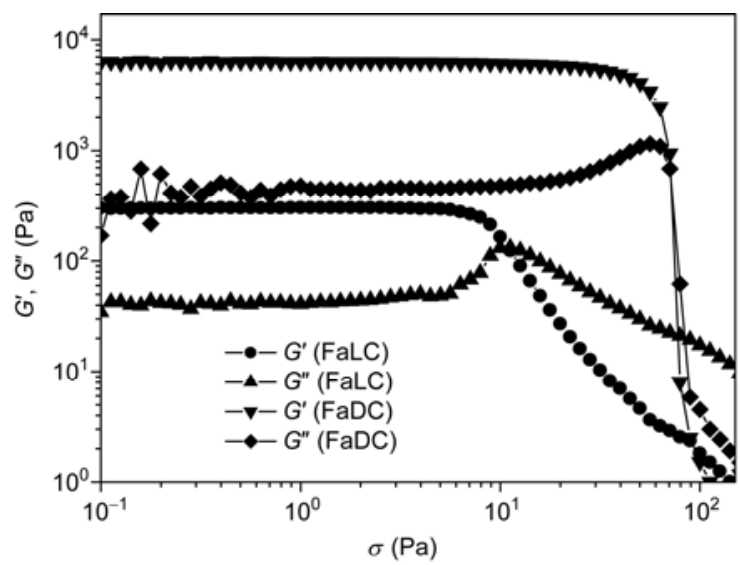

Figure 4 Determination of the linear viscoelastic region. Measurement of the evolution of $G^{\prime}$ and $G^{\prime \prime}$ as a function of the applied shear stress of the gels of $2.0 \%$ (w/v) $\mathrm{FaDC} / n$-nonane and $\mathrm{FaLC} / n$-nonane at $20^{\circ} \mathrm{C}$.

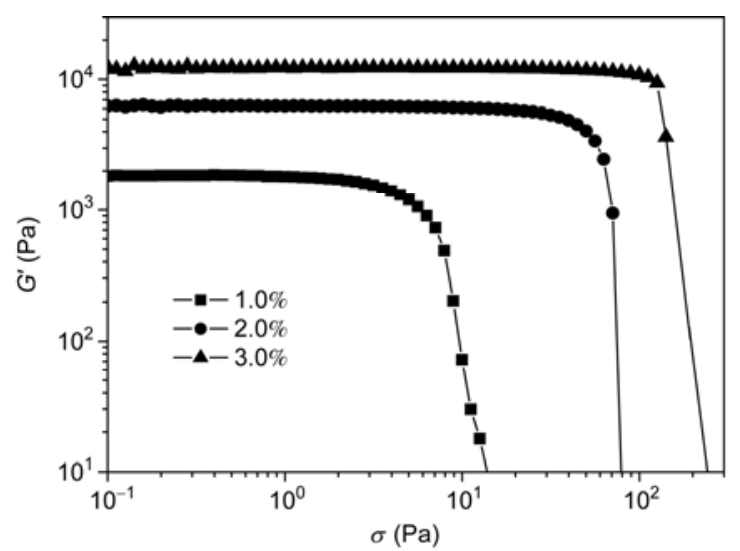

Figure 5 Determination of the linear viscoelastic region. Measurement of the evolution of $G^{\prime}$ as a function of the applied shear stress of the gels at different concentrations of $\mathrm{FaDC} / n$-nonane at $20^{\circ} \mathrm{C}$.

Figure 5, it can be seen that in the linear viscoelastic region, the value of $G^{\prime}$ increases from only 1851 to $12750 \mathrm{~Pa}$ along with increasing the gelator concentration from $1.0 \%$ to $3.0 \%$ (w/v), and correspondingly, the yield stress changes from only 9 to $141 \mathrm{~Pa}$, indicating that both the mechanical stability of the gel network and the elastic property of the gel depend well upon the concentration of the gelator [22].

As mentioned above, one of the two rheological criteria required for a stable gel is the independence of $G^{\prime}$ on the oscillatory frequency. Finally, the gel of $\mathrm{FaDC} / n$-nonane $(2 \%, \mathrm{w} / \mathrm{v})$ was subjected to frequency sweep measurement. It appears from Figure 6 that the linear viscoelastic frequency sweep response of the gel exhibits weak frequency dependence from 0.1 to $100 \mathrm{~Hz}$ (with the modulus $G^{\prime}>>G^{\prime \prime}$ ), demonstrating that an ordinary, highly elastic gel has been formed $[46,47]$. It has to be emphasized that the gel was very fragile, and the $G^{\prime}$ and $G^{\prime \prime}$ are independent of the oscillation frequency, which is also true for many other gels.

\section{$2.5 \quad$ FT-IR spectroscopy}

FTIR spectra can give profitable information for confirming formation of hydrogen bonding during the gelation process. 


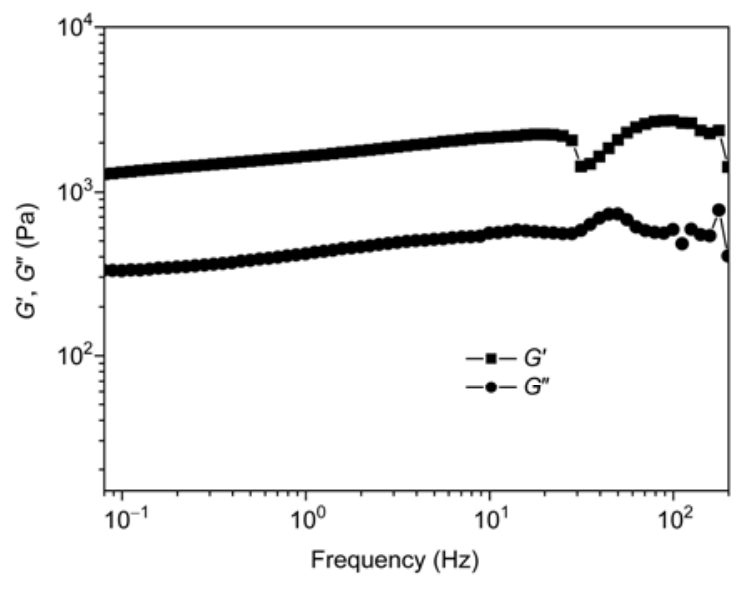

Figure 6 Dynamic moduli, $G^{\prime}$ and $G^{\prime \prime}$ vs frequency for a $2 \%(\mathrm{w} / \mathrm{v})$ gel of $\mathrm{FaDC}$ in $n$-nonane at $20^{\circ} \mathrm{C}$. Stress amplitude $=1 \mathrm{~Pa}$.

Accordingly, the FTIR spectra of FaDC/cyclohexane gel and its control system, $\mathrm{FaDC} / \mathrm{CDCl}_{3}$ solution, were recorded and the results are shown in Figure 7. From the spectrum of $\mathrm{FaDC} / \mathrm{CDCl}_{3}$ solution, it can be observed that the two typical bands of FaDC corresponding to the stretching and bending vibrations of $\mathrm{NH}$ appeared at 3346 and $1543 \mathrm{~cm}^{-1}$, respectively. However, the bands shifted to 3292 and 1547 $\mathrm{cm}^{-1}$ in the spectrum of the cyclohexane gel of $\mathrm{FaDC}$, respectively, a direct evidence for the participation of $\mathrm{NH}$ group and $\mathrm{C}=\mathrm{O}$ group in the formation of hydrogen bonding [29], which should be one of the driving forces for the formation of the gel network. Similar spectral shifts were also found in other gel systems (Table 3). It is a little bit surprising that the direction of the spectral shifts of MaLC system is different from other gel systems (Table 3), indicating that a different aggregation mode might be adopted by this system [48]. Similar phenomena were reported by our group before [22].

\section{$2.6{ }^{1}$ H NMR spectroscopy}

To obtain further information about the formation mechanism of the gel networks, the aggregation behaviors of MaDC and $\mathrm{FaDC}$ in $\mathrm{CDCl}_{3}$ solutions were studied in detail by employing temperature- and concentration-dependent ${ }^{1} \mathrm{H}$ NMR techniques, respectively. The results are shown in Figure 8. With reference to Figure 8(a), it is clear that the N-H protons of MaDC shifted from 8.33 to 8.19 with increasing the temperature of the solution from 298 to $318 \mathrm{~K}$. The observed shifts should be a result of weakening of intermolecular or intramolecular hydrogen-bonding interactions. As only intermolecular hydrogen-bonding interaction between neighboring gelator molecules is responsible for the aggregation of gelator molecules, it is necessary to distinguish the two interactions. Therefore, the concentration-dependent ${ }^{1} \mathrm{H}$ NMR of MaDC measurement was also measured and shown in Figure $8\left(\mathrm{a}^{\prime}\right)$. In this case, it is seen that the $\mathrm{N}-\mathrm{H}$ protons

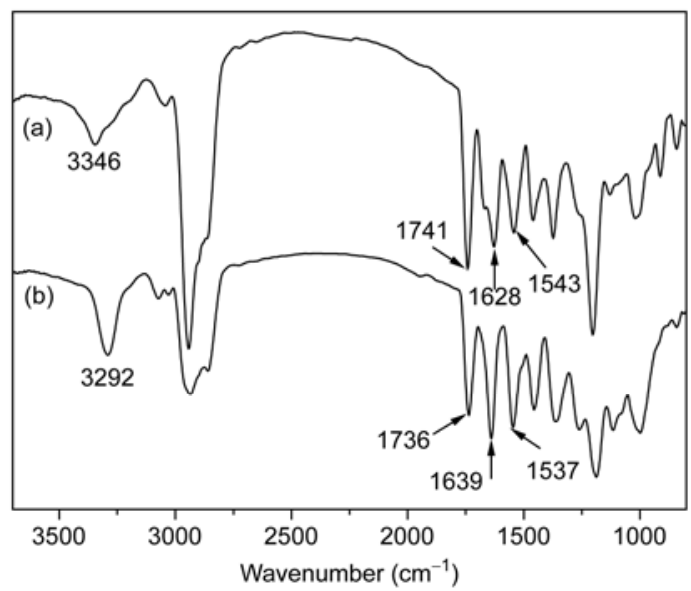

Figure 7 FTIR spectra of a solution of $\mathrm{FaDC}$ in $\mathrm{CDCl}_{3}$ (a) and a gel of FaDC in benzene (b)

Table 3 FTIR data for the solutions of the three gelators in $\mathrm{CDCl}_{3}$ and the gels of MaDC/DMSO, MaLC/cyclohexane and FaLC/benzene

\begin{tabular}{llcccc}
\hline & & \multicolumn{4}{c}{$\lambda_{\max }\left(\mathrm{cm}^{-1}\right)$} \\
\cline { 3 - 6 } & & NH stretch & NH bend & $\mathrm{C}=\mathrm{O}$ amide & $\mathrm{C}=\mathrm{O}$ ester \\
\hline \multirow{2}{*}{ MaDC } & Solution & 3277 & 1539 & 1634 & 1738 \\
& Gel & 3234 & 1551 & 1600 & 1736 \\
\multirow{4}{*}{ MaLC } & Solution & 3439 & 1533 & 1630 & 1732 \\
& Gel & 3385 & 1529 & 1632 & 1740 \\
\multirow{2}{*}{ FaLC } & Solution & 3290 & 1539 & 1651 & 1539 \\
& Gel & 3288 & 1545 & 1639 & 1738 \\
\hline
\end{tabular}

of MaDC shifted slightly to low field with increasing the concentration of the gelator from $2.0 \%$ to $4.0 \%(\mathrm{w} / \mathrm{v})$, indicating the presence of intermolecular hydrogen bonding, even though they are very weak [49]. However, the signal $(\delta=$ 6.08) of the protons $\mathrm{CO}-\mathrm{CH}=\mathrm{CH}-\mathrm{CO}$ did not shift basically in both cases, in support of the tentative conclusion that there is no $\pi-\pi$ interaction between the molecules of this MaDC. Thus, the intermolecular hydrogen-bonding is a main driving force for the gelation of the solvent by MaDC. As for compound $\mathrm{FaDC}$ in Figure 8(b) and $\left(\mathrm{b}^{\prime}\right)$, the signals of $\mathrm{N}-\mathrm{H}$ protons and the $\mathrm{CO}-\mathrm{CH}=\mathrm{CH}-\mathrm{CO}$ protons shifted from 6.64 and 6.99 to 6.37 and 6.88 , respectively, with increasing the temperature from 298 to $318 \mathrm{~K}$, and from 6.64 and 6.99 to 6.81 and 7.04, respectively, with increasing the concentration of the gelator from $2.0 \%$ to $4.0 \%(\mathrm{w} / \mathrm{v})$. Compared with the signal shifting of MaDC, the signal of $\mathrm{CO}-\mathrm{CH}=\mathrm{CH}-\mathrm{CO}$ protons of $\mathrm{FaDC}$ shifted more remarkably, indicating clearly that there are not only intermolecular hydrogen-bonding but also $\pi-\pi$ stacking in the gel of FaDC, which play very important roles in the self-assembly of the gelator molecules. Similar phenomena were also found for other gel systems (Table 4). The difference of the chemical shift between the cis- and trans-isomers demonstrated 

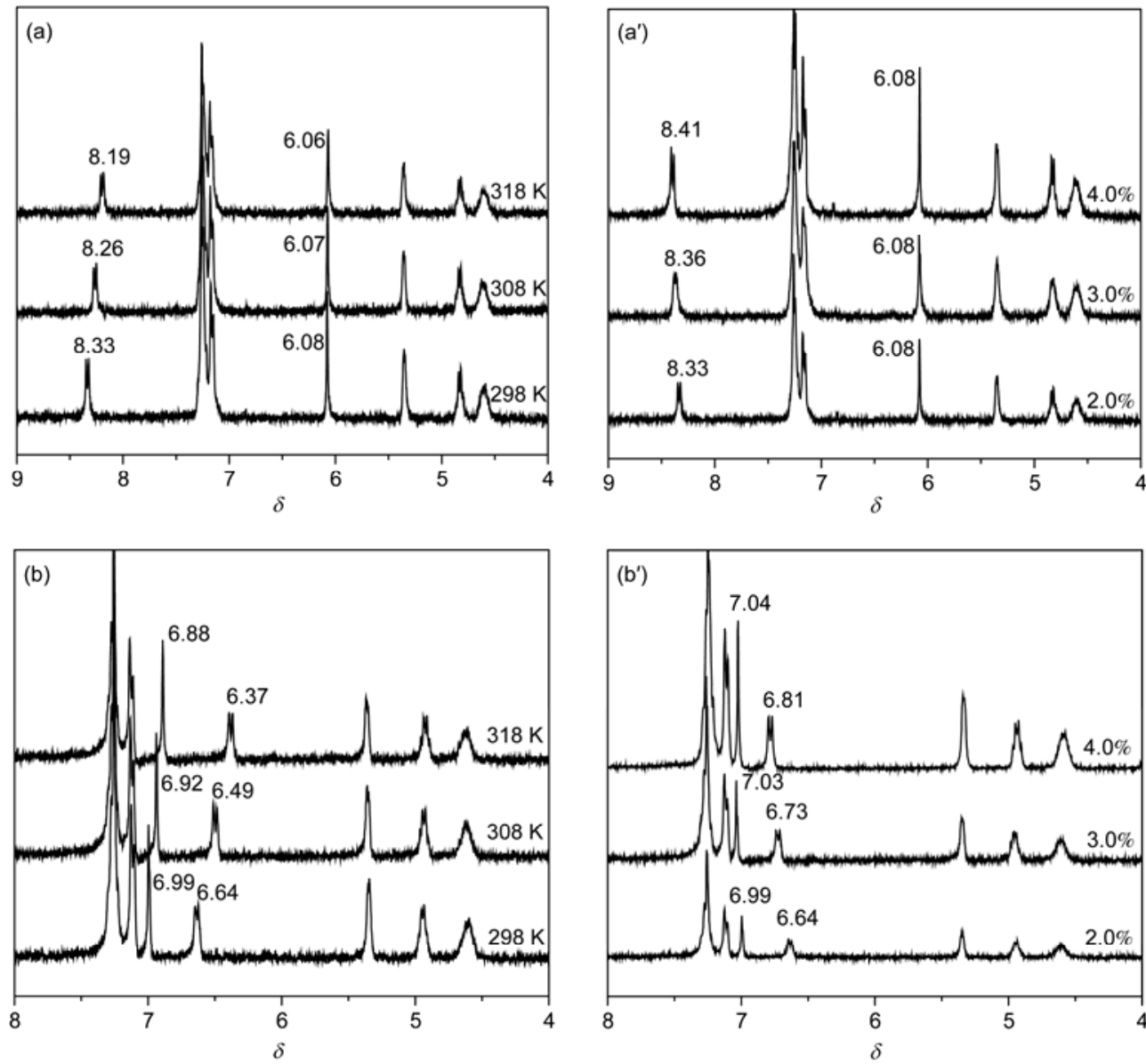

Figure 8 Partial ${ }^{1} \mathrm{H}$ NMR spectra of $\mathrm{MaDC}$ and $\mathrm{FaDC}$ in $\mathrm{CDCl}_{3}$. (a), (b) Temperature dependence at a concentration of $2.0 \%$ (w/v) $\mathrm{MaDC}$ and $\mathrm{FaDC}$ in $\mathrm{CDCl}_{3}$, respectively. $\left(\mathrm{a}^{\prime}\right),\left(\mathrm{b}^{\prime}\right)$ Concentration (w/v) dependence at $298 \mathrm{~K}$ of $\mathrm{MaDC}$ and $\mathrm{FaDC}$ in $\mathrm{CDCl}_{3}$, respectively.

Table 4 Chemical shifting data of the temperature- and concentration-dependent ${ }^{1} \mathrm{H}$ NMR for the solutions of the MaLC and $\mathrm{FaLC}_{\text {in }} \mathrm{CDCl}_{3}$

\begin{tabular}{|c|c|c|c|c|c|c|}
\hline \multirow{2}{*}{ Compound } & \multirow{2}{*}{$\begin{array}{c}T(\mathrm{~K}) \\
(2.0 \%, \mathrm{w} / \mathrm{v})\end{array}$} & \multicolumn{2}{|r|}{$\delta$} & \multirow{2}{*}{$C(\%, \mathrm{w} / \mathrm{v})(298 \mathrm{~K})$} & \multicolumn{2}{|r|}{$\delta$} \\
\hline & & $\mathrm{N} H$ & $\mathrm{CO}-\mathrm{CH}=\mathrm{C} H-\mathrm{CO}$ & & $\mathrm{N} H$ & $\mathrm{CO}-\mathrm{CH}=\mathrm{CH}-\mathrm{CO}$ \\
\hline \multirow{3}{*}{ MaLC } & 298 & 8.34 & 6.06 & 2.0 & 8.34 & 6.08 \\
\hline & 308 & 8.26 & 6.06 & 3.0 & 8.40 & 6.08 \\
\hline & 318 & 8.19 & 6.07 & 4.0 & 8.41 & 6.08 \\
\hline \multirow{3}{*}{ FaLC } & 298 & 6.92 & 6.53 & 2.0 & 6.92 & 6.53 \\
\hline & 308 & 6.88 & 6.41 & 3.0 & 6.94 & 6.65 \\
\hline & 318 & 6.85 & 6.31 & 4.0 & 7.00 & 6.79 \\
\hline
\end{tabular}

clearly that the configuration of the diacid moieties has a significant impact on the self-assembly of the gelators, and explained why the gelation ability of trans-isomers is much better than that of cis-isomers.

\subsection{Model}

On the bases of the results and discussions described above, possible aggregation model of both trans- and cis-ismers in benzene was proposed and schematically represented in
Scheme 2. One-dimensional superstructures of FaDC are driven by the van der Waals interactions between the cholesteryl units, $\pi-\pi$ stacking between trans-ethylenic linkage of the fumaric acid moieties and $\mathrm{H}$-bonding between $\mathrm{N}-\mathrm{H}$ and $\mathrm{C}=\mathrm{O}$, thus self-assemble into thin fibers, which are further aggregated into beehive-like structures. However, in the case of MaDC, the weakening of van der Waals interaction between cholesteryl moieties [30], the breaking or reforming of the hydrogen bonding [28,29], and the vanishing of the $\pi-\pi$ stacking lead to dissolution of MaDC in benzene. 


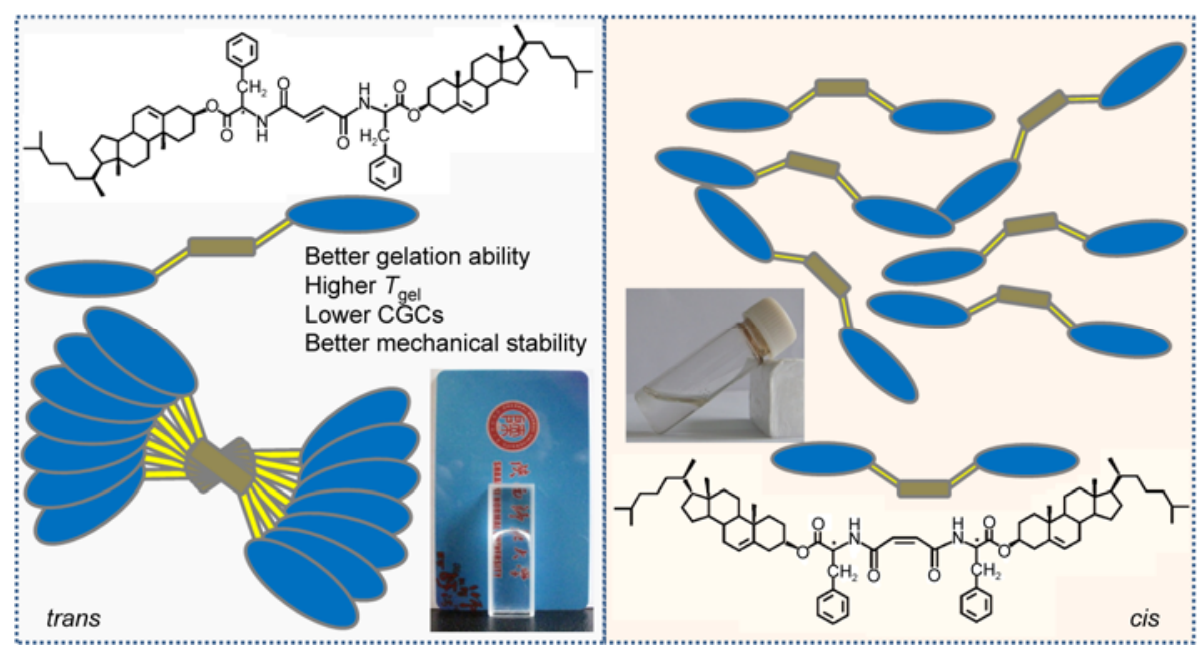

Scheme 2 Schematic representation of the formation mechanism of the aggregates of FaDC and MaDC in benzene.

\subsection{Selective gelation of benzene from its mixture with water}

With careful reference to Table 1, we can find that both FaDC and FaLC display remarkable ability to gelate benzene, toluene and xylene at room temperature without the heating-cooling process or addition of another co-solvent. Therefore, it is possible for FaDC and FaLC to gelate these organic solvents selectively from their mixtures with water, i.e. selective gelation. Selective gelation of organic solvents, such as commercial oil and aromatic solvents, from their mixtures with water is of crucial importance in view of its potential applications in oil extraction, collection of leaked oil, and purification of water contaminated by oil $[26,50,51]$. In fact, $\mathrm{FaDC}$ can gelate benzene assuredly and selectively from water without heating. Figure 9 shows a typical process of the selective gelation of benzene by FaDC from a benzene/water mixture. In the experiment, $2 \mathrm{~mL}$ water was mixed with $0.5 \mathrm{~mL}$ benzene in a vial of $5 \mathrm{~mL}$, then a small amount of FaDC was added, and then the vial was shaken gently until FaDC was dissolved. After a while, an organogel

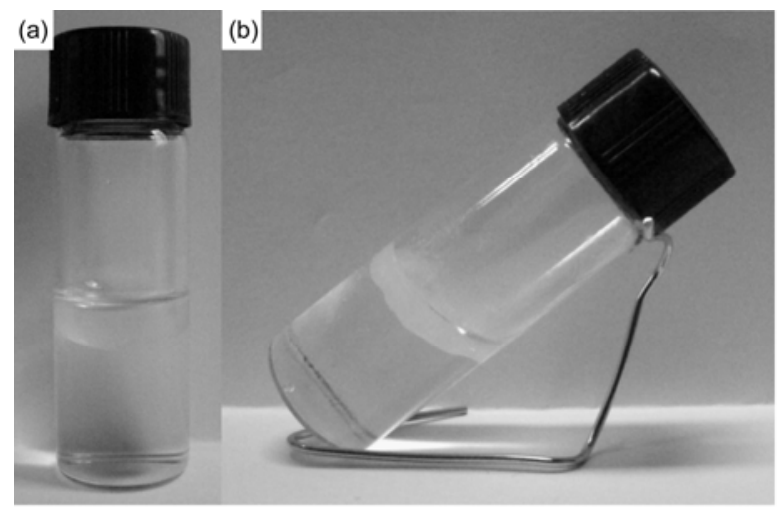

Figure 9 (a) $2 \mathrm{~mL}$ water and $0.5 \mathrm{~mL}$ benzene; (b) selective gelation of benzene layer by $\mathrm{FaDC}$ at room temperature. formed and floated in the water. Interestingly, the same phenomenon was also observed in other room-temperature gel systems, suggesting that this kind of gelators might have a possibility to be used in the purification of water.

In order to certify that $\mathrm{FaDC}$ can be used in the purification of water, we added some rhodamine B, a well-known and water-soluble dye, into water and tried to separate it from water via selective gelation. To the dye-polluted water, $0.5 \mathrm{~mL}$ benzene was added, and the color of the water phase disappeared with shaking due to the extraction of the dye by benzene. After that, $0.01 \mathrm{~g} \mathrm{FaDC}$ was added to the mixture, and the tube was shaken again until there was no solid left in the mixture. After several minutes, the benzene phase became a gel. Obviously, as a gel, the benzene phase was easily separated from the mixture, and thereby the contaminated water was purified. The efficiency of the purification was confirmed by fluorescence measurement (Figure 10),

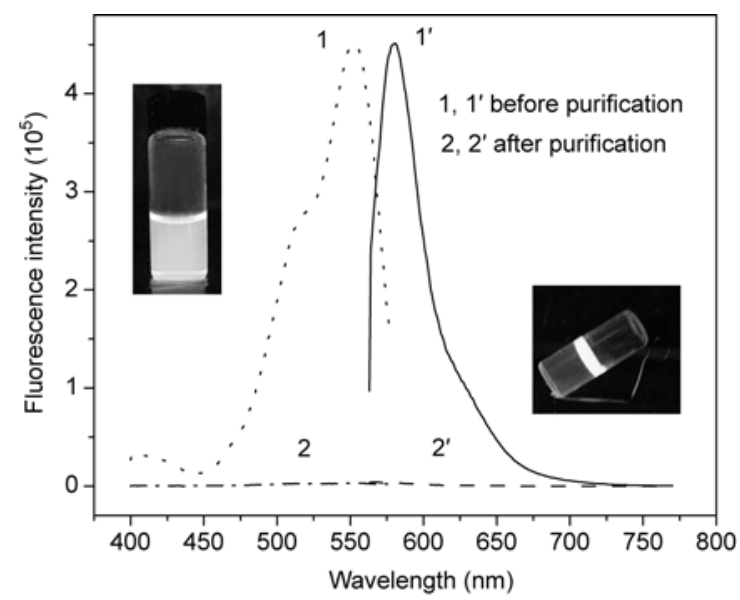

Figure 10 Fluorescence excitation and emission spectra of the purification of rhodamine B-polluted water. $\lambda_{\mathrm{ex}}=553 \mathrm{~nm}, \lambda_{\mathrm{em}}=577 \mathrm{~nm}$. Inset: photos of $2 \mathrm{~mL}$ aqueous solution of rhodamine $\mathrm{B}$ and selective gelation of benzene layer with rhodamine B by FaDC at room temperature under a $365 \mathrm{~nm}$ UV lamp. 
and the purification efficiency is more than $97 \%$, suggesting that this method is feasible at least at a bench scale. The similar attempts were also reported by other group [52] and us [26].

\section{Summary}

In summary, four di-cholesterol-based gelators with different spatial configurations (MaDC, FaDC, MaLC and FaLC) have been designed and synthesized. And their gelation properties have been tested in 26 organic solvents. Gelation test revealed that $\mathrm{FaDC}$ has the strongest gelation ability among the four isomers. Importantly, the trans-configuration is more helpful for the gelation, but the chirality of the linker is of less importance for the gelation. Interestingly, $\mathrm{FaDC}$ and FaLC show phase-selective gelation of aromatic solvents from their mixtures with water without heating-cooling process at room temperature, which establishes a foundation for the possibility of the purification of polluted water. SEM and CD spectroscopy studies revealed that the spatial configuration of the linkers of gelators has a significant impact on the aggregation mode, the morphologies and the chirality of the networks of the gels. Moreover, the different aggregation behaviors also have an impact on mechanical properties of the gels, which were consistent with rheological studies. Furthermore, temperature- and concentration-dependent ${ }^{1} \mathrm{H}$ NMR and FTIR measurements demonstrated that intermolecular hydrogen bonding and $\pi-\pi$ stacking are important driving forces for the formation of the gels.

This work was supported by the National Natural Science Foundation of China (20902055, 20927001, 91027017, 21273141), the 13115 Project of Shaanxi Province (2010ZDKG-89), and the Program for Changjiang Scholars and Innovative Research Team in University of China (IRT1070).

1 Adhikari B, Banerjee A. Short-peptide-based hydrogel: A template for the in situ synthesis of fluorescent silver nanoclusters by using sunlight. Chem Eur J, 2010, 16: 13698-13705

2 Dowling T C, Arjomand M A, Lin E T, et al. Relative bioavailability of ketoprofen $20 \%$ in a poloxamer-lecithin organogel. Am J HealthSyst Pharm, 2004, 61: 2541-2544

3 Sawant P D, Liu X Y. Formation and novel thermomechanical processing of biocompatible soft materials. Chem Mater, 2002, 14: 3793-3798

4 Yang Y G, Suzuki M, Shirai H, et al. Nanofiberization of inner helical mesoporous silica using chiral gelator as template under a shear flow. Chem Commun, 2005: 2032-2034

5 Xue P C, Lu R, Li D M, et al. Novel CuS nanofibers using organogel as a template: Controlled by binding sites. Langmuir, 2004, 20 : $11234-11239$

6 Holtz J H, Asher S A. Polymerized colloidal crystal hydrogel films as intelligent chemical sensing materials. Nature, 1997, 389: 829-832

7 Kanga L, Liub X Y, Sawantb P D, et al. SMGA gels for the skin permeation of haloperidol. J Controlled Release, 2005, 106: 88-98

8 Hikmet R A M, Kemperman H. Electrically switchable mirrors and optical components made from liquid-crystal gels. Nature, 1998, 392: 476-479

9 Khatua D, Dey J. Spontaneous formation of gel emulsions in organic solvents and commercial fuels induced by a novel class of amino acid derivatized surfactants. Langmuir, 2005, 21: 109-114

10 Zhang M M, Sun S T, Yu X D, et al. Formation of a large-scale ordered honeycomb pattern by an organogelator via a self-assembly process. Chem Commun, 2010, 46: 3553-3555

11 Sugiyasu K, Fujita N, Shinkai S. Fluorescent organogels as templates for sol-gel transcription toward creation of optical nanofibers. J Mater Chem, 2005, 15: 2747-2754

12 John G, Vemula P K. Design and development of soft nanomaterials from biobased amphiphiles. Soft Matter, 2006, 2: 909-914

13 Sangeetha N M, Maitra U. Supramolecular gels: Functions and uses. Chem Soc Rev, 2005, 34: 821-836

14 Terech P, Weiss R G. Low molecular mass gelators of organic liquids and the properties of their gels. Chem Rev, 1997, 97: 3133-3159

15 Esch J H v, Feringa B L. New functional materials based on selfassembling organogels: From serendipity towards design. Angew Chem Int Ed, 2000, 39: 2263-2266

16 Lin Y C, Weiss R G. Liquid-crystalline solvents as mechanistic probes. 24. A novel gelator of organic liquids and the properties of its gels. Macromolecules, 1987, 20: 414-417

17 Žinić M, Vögtle F, Fages F. Cholesterol-based gelators. Top Curr Chem, 2005, 256: 39-76

18 Gao D, Xue M, Peng J X, et al. Preparation and gelling properties of sugar-contained low-molecular-mass gelators: Combination of cholesterol and linear glucose. Tetrahedron, 2010, 66: 2961-2968

19 Liu K Q, Yan N, Peng J X, et al. Supramolecular gels based on organic diacid monoamides of cholesteryl glycinate. J Colloid Interface Sci, 2008, 327: 233-242

20 Li Y G, Liu K Q, Liu J, et al. Amino acid derivatives of cholesterol as "latent" organogelators with hydrogen chloride as a protonation reagent. Langmuir, 2006, 22: 7016-7020

21 Peng J X, Xia H Y, Liu K Q, et al. Water-in-oil gel emulsions from a cholesterol derivative: Structure and unusual properties. J Colloid Interface Sci, 2009, 336: 780-785

22 Peng J X, Liu K Q, Liu J, et al. New dicholesteryL-based gelators: Chirality and spacer length effect. Langmuir, 2008, 24: 2992-3000

23 Peng J X, Liu K Q, Liu X F, et al. New dicholesteryl-based gelators: Gelling ability and selective gelation of organic solvents from their mixtures with water at room temperature. New J Chem, 2008, 32: 2218-2224

24 Liu J, Yan J L, Yuan X W, et al. A novel low-molecular-mass gelator with a redox active ferrocenyl group: Tuning gel formation by oxidation. J Colloid Interface Sci, 2008, 318: 397-404

25 Liu J, He P L, Yan J L, et al. An organometallic super-gelator with multiple-stimulus responsive properties. Adv Mater, 2008, 20: 25082511

26 Xue M, Gao D, Liu K Q, et al. Cholesteryl derivatives as phaseselective gelators at room temperature. Tetrahedron, 2009, 65: 33693377

27 Xue M, Liu K Q, Peng J X, et al. Novel dimeric cholesteryl-based A(LS)2 low-molecular-mass gelators with a benzene ring in the linker. J Colloid Interface Sci, 2008, 327: 94-101

28 Koumura N, Kudo M, Tamaoki N. Photocontrolled gel-to-sol-tolgel phase transitioning of meta-substituted azobenzene bisurethanes through the breaking and reforming of hydrogen bonds. Langmuir, 2004, 20: 9897-9900

29 Kim J H, Seo M, Kim Y J, et al. Rapid and reversible gel-sol transition of self-assembled gels induced by photoisomerization of dendritic azobenzenes. Langmuir, 2009, 25: 1761-1766

30 Wu Y P, Wu S, Tian X J, et al. Photoinduced reversible gel-sol transitions of dicholesteroL-linked azobenzene derivatives through breaking and reforming of van der Waals interactions. Soft Matter, 2011, 7: 716-721

31 Murata K, Aoki M, Suzuki T, et al. Thermal and light control of the sol-gel phase transition in cholesterol-based organic gels. Novel helical aggregation modes as detected by circular dichroism and electron microscopic observation. J Am Chem Soc, 1994, 116: 66646676

32 Zhou Y F, Xu M, Wu J C, et al. A novel photo-responsive organogel 
based on azobenzene. J Phys Org Chem, 2008, 21: 338-343

33 Ran X, Wang $\mathrm{H} \mathrm{T}$, Zhang $\mathrm{P}$, et al. Photo-induced fiber-vesicle morphological change in an organogel based on an azophenyl hydrazide derivative. Soft Matter, 2011, 7: 8561-8566

34 Geiger C, Stanescu M, Chen L, et al. Organogels resulting from competing self-assembly units in the gelator: Structure, dynamics, and photophysical behavior of gels formed from cholesterol-stilbene and cholesterol-squaraine gelators. Langmuir, 1999, 15: 2241-2245

35 Miljanić S, Frkanec L, Meić Z, et al. Photoinduced gelation by stilbene oxalyl amide compounds. Langmuir, 2005, 21: 2754-2760

36 Miljanic S, Frkanec L, Meic Z, et al. Gelation ability of novel oxamide-based derivatives bearing a stilbene as a photo-responsive unit. Eur J Org Chem, 2006: 1323-1334

37 Frkanec L, Jokić M, Makarević J, et al. Bis(PheOH) maleic acid amide-fumaric acid amide photoizomerization induces microsphereto-gel fiber morphological transition: The photoinduced gelation system. J Am Chem Soc, 2002, 124: 9716-9717

38 Oda R, Huc I, Candau S J. Gemini surfactants as new, low molecular weight gelators of organic solvents and water. Angew Chem Int Ed, 1998, 37: 2689-2691

39 Berthier D, Buffeteau T, Léger J M, et al. From chiral counterions to twisted membranes. J Am Chem Soc, 2002, 124: 13486-13494

40 Takahashi A, Sakai M, Kato T. Melting temperature of thermally reversible gel. VI. Effect of branching on the soL-gel transition of polyethylene gels. Polym J, 1980, 12: 335-341

41 Li Y G, Fang Y, Liu J, et al. Synthesis and gelation behavior of cholesteryl glycinate anthraquinone-2-carboxylamide and cholesteryl glycinate 9,10-dimethyloxyl anthracene-2-carboxylamide. J Chin Chem Soc, 2006, 53: 359-366

42 Menger F M, Peresypkin A V. Strings of vesicles: Flow behavior in an unusual type of aqueous gel. J Am Chem Soc, 2003, 125: 5340-5345
43 Yao S, Beginn U, Gress T, et al. Supramolecular polymerization and gel formation of bis(merocyanine) dyes driven by dipolar aggregation. J Am Chem Soc, 2004, 126: 8336-8348

44 Piepenbrock M-O M, Lloyd G O, Clarke N, et al. Metal- and anion-binding supramolecular gels. Chem Rev, 2010, 110: 19602004

45 Das A, Ghosh S. Contrasting self-assembly and gelation properties among bis-urea- and bis-amide-functionalised dialkoxynaphthalene (DAN) p systems. Chem Eur J, 2010, 16: 13622-13628

46 Xing B G, Yu C W, Chow K H, et al. Hydrophobic interaction and hydrogen bonding cooperatively confer a vancomycin hydrogel: A potential candidate for biomaterials. J Am Chem Soc, 2002, 124: 14846-14847

47 Wang Y J, Tang L M, Yu J. Investigation of spontaneous transition from low-molecular-weight hydrogel into macroscopic crystals. Cryst Growth Des, 2008, 884-889

48 Li J L, Liu X Y, Strom C S, et al. Engineering of small molecule organogels by design of the nanometer structure of fiber networks. Adv Mater, 2006, 18: 2574-2578

49 Yan N, He G, Zhang H L, et al. Glucose-based fluorescent lowmolecular mass compounds: Creation of simple and versatile supramolecular gelators. Langmuir, 2010, 26: 5909-5917

50 Bhattacharya S, Krishnan-Ghosh Y. First report of phase selective gelation of oil from oil/water mixtures. Possible implications toward containing oil spills. Chem Commun, 2001: 185-186

51 Suzuki M, Sato T, Shirai H, et al. Powerful low-molecular-weight gelators based on L-valine and L-isoleucine with various terminal groups. New J Chem, 2006, 30: 1184-1191

52 Ray S, Das A K, Banerjee A. pH-responsive, bolaamphiphile-based smart metallo-hydrogels as potential dye-adsorbing agents, water purifier, and vitamin B12 carrier. Chem Mater, 2007, 19: 1633-1639

Open Access This article is distributed under the terms of the Creative Commons Attribution License which permits any use, distribution, and reproduction in any medium, provided the original author(s) and source are credited. 